\title{
A dynamic water accounting framework based on marginal resource opportunity cost
}

\author{
A. Tilmant ${ }^{1}$, G. Marques ${ }^{2}$, and Y. Mohamed ${ }^{3,4}$ \\ ${ }^{1}$ Department of Civil and Water Engineering, Université Laval, Québec, Canada \\ ${ }^{2}$ Universidade Federal do Rio Grande do Sul, UFRGS Porto Alegre, Porto Alegre, RS, Brazil \\ ${ }^{3}$ Hydraulic Research Center, P.O. Box 318, Wad Medani, Sudan \\ ${ }^{4}$ UNESCO-IHE, Delft, the Netherlands \\ Correspondence to: A. Tilmant (amaury.tilmant@me.com)
}

Received: 2 September 2014 - Published in Hydrol. Earth Syst. Sci. Discuss.: 23 October 2014

Revised: - - Accepted: 17 February 2015 - Published: 23 March 2015

\begin{abstract}
Many river basins throughout the world are increasingly under pressure as water demands keep rising due to population growth, industrialization, urbanization and rising living standards. In the past, the typical answer to meet those demands focused on the supply side and involved the construction of hydraulic infrastructures to capture more water from surface water bodies and from aquifers. As river basins have become more and more developed, downstream water users and ecosystems have become increasingly dependent on the management actions taken by upstream users. The increased interconnectedness between water users, aquatic ecosystems and the built environment is further compounded by climate change and its impact on the water cycle. Those pressures mean that it has become increasingly important to measure and account for changes in water fluxes and their corresponding economic value as they progress throughout the river system. Such basin water accounting should provide policy makers with important information regarding the relative contribution of each water user, infrastructure and management decision to the overall economic value of the river basin. This paper presents a dynamic water accounting approach whereby the entire river basin is considered as a value chain with multiple services including production and storage. Water users and reservoir operators are considered as economic agents who can exchange water with their hydraulic neighbors at a price corresponding to the marginal value of water. Effective water accounting is made possible by keeping track of all water fluxes and their corresponding hypothetical transactions using the results of a
\end{abstract}

hydro-economic model. The proposed approach is illustrated with the Eastern Nile River basin in Africa.

\section{Introduction}

As water resources are increasingly used for various purposes, there is a need for a unified framework to describe, quantify and classify water use in a region, be it a catchment, a river basin or a country. The first water accounting exercises focused on the physical resource, trying to describe the status of water resource use and consequences of water-resourcesrelated actions (Molden, 1997). Water accounting procedures were quickly enriched by linking water use to relevant productivity indicators (Molden and Sakthivadivel, 1999) in order to provide water managers with strategic information on water allocation in a region. This information can then be used to design water saving strategies, to examine the potential for water reallocation, to identify water using activities that require more detailed analysis, etc.

The success of water accounting is such that it has become an integral part of environmental water accounts in many countries, such as Australia (Vardon et al., 2007), and by the United Nations through the System of EnvironmentalEconomic Accounting for Water (SEEA-Water). Although it is increasingly adopted, there is no unified procedure to established water accounts, nor is there an agreement on how water accounts must be presented.

National water accounts typically aggregate water use data at a scale corresponding to the economic data that are used 
to establish national income accounts, which rarely coincide with hydrologic boundaries. This aggregation has an important limitation: national water accounts should not be used directly to design policy interventions at a lower scale, like the river basin scale. In closed river basins, for instance, the aggregation implies that water accounts do not properly capture the interconnectedness amongst water users, as well as between water users and ecosystems.

However, with the availability of both sophisticated hydrologic models and remote sensing data, hydrologists are now able to track water fluxes in complex river basins. When linked to productivity indicators, detailed water accounts can be established in which various watershed processes are represented. Kirby and Mainuddin (2006), for example, propose a water account of the Mekong River basin in which water supplies and demands are aggregated at the sub-basin scale. Zhu et al. (2009) describe the water accounting system in the Yellow River basin in China and discuss the specificities of the Chinese water accounting system. Karimi et al. (2013a) present Water Accounting Plus (WA+), an extension of the water accounting framework proposed by the International Water Management Institute (IWMI) in the 1990s. The extension allows for the consideration of more watershed processes including the important role of land use. The new framework is implemented in the Indus Basin (Karimi et al., 2013b). A water accounting framework for an international river basin, the Orange River in southern Africa, is discussed in Lange et al. (2007). Their framework is largely based on information from each country's national water accounts.

Since many water accounts are established on an annual basis, the relationship between the seasonal hydrologic variability and water productivity cannot be analyzed. Hence, policy interventions requiring finer temporal and spatial scales, such as drought management, cannot be guided by traditional water accounting methods. Kirby and Mainuddin (2006) address this issue and propose a dynamic, seasonal, water accounting approach in which the major water uses are considered.Those efforts are useful but the linkage to the economic data is often implicit due to the mismatch between the spatial and temporal scales of the hydrologic and economic variables. Moreover, storage services are also ignored despite the fact that storage infrastructures contribute to basin-wide benefits and/or costs (Tilmant et al., 2012).

Another limitation relates to the use of water productivity (income generated in an industry per cubic meter of water used) instead of water value. Users value water at its marginal use (Griffin, 2006) and this value changes with the quantity used. Thus, by using a fixed water productivity value, the economic information produced by a water account cannot be used in situations where the quantity of water available changes (due to a drought or a water project changing supply). The benefits are likely to be overestimated, while the losses may be underestimated. The approach presented in this paper avoids this limitation by using information that better reflects the water value to the user, rather than a fixed water productivity. This makes the economic results more useful to support decisions on water system operation and expansion.

Another important contribution of this paper is that it provides a structured framework for better use and understanding of the results of hydro-economic models. The sheer amount of information produced in such models, especially in large-scale applications (like Jenkins et al., 2004), makes result interpretation often challenging. Given the increasing perception and incorporation of the water's economic value for water planning and management worldwide, it is expected that such models will bring relevant contributions in the design and operation of water systems in the years to come, turning the best use of their information equally important. The water accounting approach presented in this paper integrates critical information produced by hydroeconomic models, including the water value, storage value and dynamic water fluxes, allowing one to track the economic effects of changes (droughts, system's expansion, climate change) to individual elements in the system (users, infrastructure, the environment).

The proposed framework rests on two main observations: (i) that water scarcity demands a good understanding of water fluxes, uses and economic values for effective management; and (ii) that the marginal resource opportunity cost (MROC) of water is the best indicator to signal water scarcity. Based on these two observations, MROC is used to establish water accounts and bridge the gap between hydrological and economic processes. The MROC of water is an indicator of the aggregated economic impact of water scarcity and how much the users would be willing to pay (WTP) to mitigate that scarcity (Pulido-Velazquez et al., 2013). In other words, it corresponds to the at-source marginal value of water (Tilmant et al., 2008), which varies in space and time according to several factors including the (relative) imbalance between supply and demand, the topology (hydraulic connectivity) and nature of water uses (e.g., rival versus nonrival). MROC is best determined with hydro-economic models that integrate essential hydrologic, economic and institutional information of a river basin in a single, coherent, computational framework. Pande et al. (2011), for example, use a hydro-economic model to analyze the interdependence between various hydrological processes and the marginal value of water at the sub-basin scale. Kiptala et al. (2014) attempt to link the hydro-economics of green water use in the upper catchments of the Pangani Basin, with the blue water use further downstream in the main stem of the river.

To establish water accounts based on MROC, the basic idea is to exploit the results of optimization-based hydroeconomic models and combine allocation decisions with their corresponding marginal water values. In other words, by tracking water allocation decisions, including storage, and the spatial and temporal changes in the marginal value of water, one can establish economically based, dynamic, wa- 
ter accounting for a system involving multiple uses (offstream and instream, rival versus non-rival) as well as multiple reservoirs). To achieve this, the framework requires the unbundling of production and storage services; that is, reservoirs are considered as separate economic agents that are financially independent of the hydraulically connected water users (e.g., farmer, power company, industry).

The paper is organized as follows. It starts with a review of hydro-economic modeling with an emphasis on the optimization-based approach and the typical results one can expect. The hydro-economic water accounting framework for a multireservoir system involving a mix of instream and offstream uses is then presented. Section 3 is devoted to the case study, which is followed by the analysis of the results. Finally, conclusions are presented in Sect. 5.

\section{Materials and method}

\subsection{Hydro-economic modeling}

Over the past 2 decades, hydro-economic modeling has emerged as one of the most common tools to analyze water resources systems, especially water resources allocation problems. Hydro-economic models usually require a network representation of the river system in order to physically connect various sources of supply with the scarcity-sensitive water demands. Recent reviews on hydro-economic modeling can be found in Harou et al. (2009), Brouwer and Hofkes (2008) and Heinz et al. (2007).

There are basically two classes of hydro-economic models: optimization-based versus simulation-based. In an optimization-based hydro-economic model, an objective function is to be maximized (or minimized) subject to physical, institutional and/or economical constraints. This prescriptive approach is often adopted by economists. Simulation-based hydro-economic models, on the other hand, are essentially descriptive in the sense that they require the allocation policies to be specified by the analyst like any other input. This second approach has emerged from the hydrological sciences and can be considered as an extension of rainfall-runoff models that are widely used in hydrology (see e.g., Seyam et al., 2002; Brown et al., 1990).

Although both approaches have their own advantages and disadvantages, the fact that an optimization-based model simultaneously determines the allocation decisions and the marginal costs of the binding constraints makes it attractive here since it will be a key feature in the proposed methodology. As it is well known in optimization theory, when an optimization problem is solved, the solution procedure not only provides the optimal decisions but also the marginal costs of the binding constraints, i.e., the limiting resources or factors that prevent further improvement of the objective function.

In a network representation of the water system, a water balance must be evaluated at each node in order to de- termine the amount of water available for the demand sites connected to that node. In other words, at a given node, the mass balance equation ensures that water is allocated to the connected water users to the extent permitted by water availability at that node. In case of water shortage, the marginal cost associated with the water balance indicates the shadow price of water, i.e., what the users would be willing to pay for an additional unit of water (Young, 2005). In situations where water is plentiful, this shadow price will be zero or even negative if the surplus causes damages (e.g like during a flood event). In the rest of this paper, the term MROC will be preferred to the shadow price of water even though they are strictly identical. MROC can, in principle, be also derived from simulation-based hydro-economic models but the procedure is more computationally demanding, especially for large networks. The basic principle is to assess the change in basin-wide benefits (costs) after changing the availability of water at a given node by one unit. The process must be repeated for all nodes and for various combinations of water availabilities throughout the system.

Let us assume that (i) the basin-wide allocation is economically efficient (i.e., there is only one decision-maker seeking to maximize the productivity of water), (ii) water users are price takers (i.e., they cannot influence the price through their production) and (iii) the main source of uncertainty comes from the hydrologic processes. With these assumptions, a water resources allocation problem in a river basin can be formulated as a centralized hydro-economic optimization problem. The objective function $Z$ to be maximized typically includes the economic net benefits across all water uses over a given planning period. Let $t$ be the index of time $(t=1,2, \ldots, T), b_{t}$ the aggregated (basin-wide) net benefits at time $t, \boldsymbol{q}_{t}$ the vector of hydrologic supply, $\boldsymbol{x}_{t}$ the vector of allocation decisions, $\boldsymbol{w}_{t}$ the vector of state variables, $\alpha$ a discount factor and $v$ a terminal value function.

With the above definitions, the objective function of the hydro-economic problem can be written as

$$
Z^{*}=\max _{\boldsymbol{x}_{t}}\left\{\underset{\boldsymbol{q}_{t}}{E}\left[\sum_{t}^{T} \alpha_{t} b_{t}\left(\boldsymbol{w}_{t}, \boldsymbol{x}_{t}\right)+\alpha_{T+1} v\left(\boldsymbol{w}_{T+1}\right)\right]\right\},
$$

where $E$ is the expectation operator and $Z^{*}$ is the total benefit associated with the optimal allocations $\left(x_{1}^{*}, x_{2}^{*}, \ldots, x_{T}^{*}\right)$.

This function will be maximized to the extent permitted by the constraints, which can be of physical, institutional or economical nature. It defines $g$ a set of functions constraining the allocation decisions, $h$ a set of functions constraining the state of the system and $f$ as a set of functions describing the transition of the system from time $t$ to time $t+1$. The optimization problem has the following set of constraints:

$g_{t+1}\left(\boldsymbol{x}_{t+1}\right) \leq 0$,

$h_{t+1}\left(\boldsymbol{w}_{t+1}\right) \leq 0$, 
$\boldsymbol{w}_{t+1}=f_{t}\left(\boldsymbol{w}_{t}, \boldsymbol{x}_{t}\right)$.

Of interest are the constraints in Eq. (4), which include the mass balance equations in the river basin:

$\boldsymbol{s}_{t+1}-\mathbf{R}\left(\boldsymbol{r}_{t}+\boldsymbol{l}_{t}\right)-\mathbf{I}\left(\boldsymbol{i}_{t}\right)+\boldsymbol{e}_{t}\left(\boldsymbol{s}_{t}, \boldsymbol{s}_{t+1}\right)=\boldsymbol{s}_{t}+\boldsymbol{q}_{t}$,

where $\boldsymbol{s}_{t}$ is the vector of storages at time $t, \boldsymbol{r}_{t}$ is the vector of controlled outflows, $\boldsymbol{l}_{t}$ is the vector of uncontrolled outflows (e.g., reservoir spillages), $\boldsymbol{i}_{t}$ is the vector of withdrawals, $\mathbf{R}$ and $\mathbf{I}$ are the connectivity matrices representing the topology of the system (including return flows), $\boldsymbol{e}_{t}$ is the vector of evaporation losses and $\boldsymbol{q}_{t}$ is the vector of incremental flows.

At the optimal solution of the optimization problem (Eqs. 1-4), the solver provides the allocation decisions $\left(x_{1}^{*}, x_{2}^{*}, \ldots, x_{T}^{*}\right)$ and the shadow prices $\left(\lambda_{1}, \lambda_{2}, \ldots, \lambda_{T}\right)$ of Eqs. (2)-(4). For Eq. (4), the shadow prices correspond to the marginal resources opportunity cost (MROC) at the sites where the water balances are computed. For example, at site $j$ and time $t$, we have

$\frac{\partial Z}{\partial\left[s_{t}(j)+\boldsymbol{q}_{t}(j)\right]}=\lambda_{t}(j)$.

As we can see in the above equation, the MROC indicates how much water users in the basin would be willing to pay for an additional unit of water at that site and at that time.

Economics theory tells us that efficient resource allocation requires that the price that users pay for resource use should equate with the MROC. If the price were less than the MROC, then the resource is overconsumed or overutilized. Conversely, a price that is higher than the MROC will lead to underconsumption/underutilization. The concept of opportunity cost is particularly useful to signal water scarcity; that is, when the value of a resource in its best alternative use, i.e., other than the purpose being considered, is positive (Griffin, 2006). If water were plentiful, then the opportunity cost would be zero because it would not be necessary to choose among alternatives. When dealing with short-term allocation problems, allocation decisions usually entail relatively small changes in resource use so that only changes at the margin are considered.

\subsection{Water accounts}

The ultimate goal of the proposed water accounting framework is to measure the contribution of each water user, infrastructure and management decision to the overall economic value of water resources in a given basin. To achieve this, the framework requires (i) the unbundling of production and storage services and (ii) the knowledge of both the allocation decisions and the corresponding MROC. Production services include a wide range of activities, ranging from the production of runoff or blue water (hydrologic services)

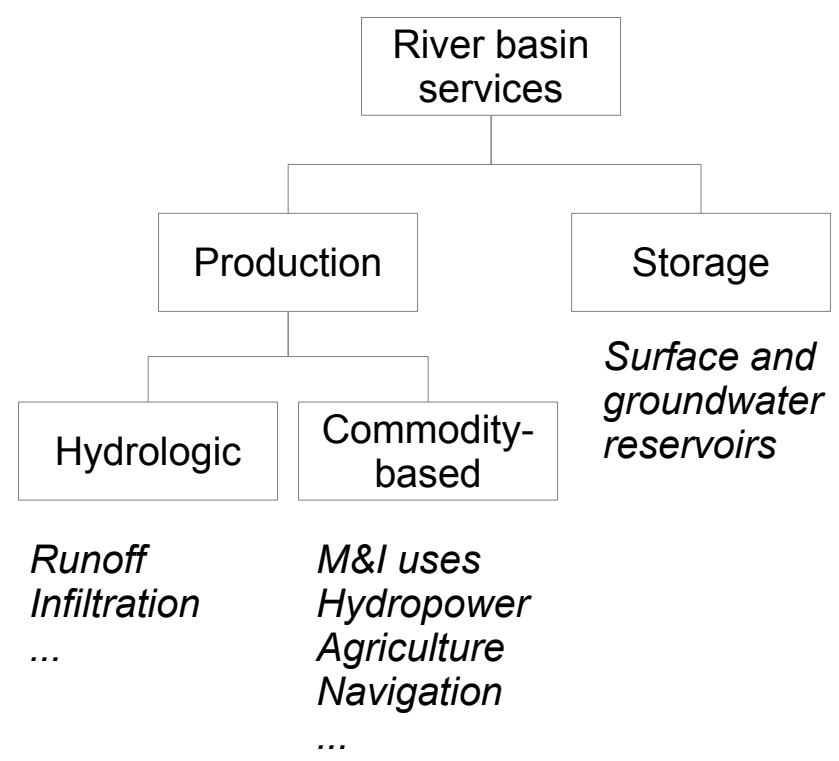

Figure 1. Production and storage services in a river basin.

as well as activities for which water can be considered as a production input (economic services): municipal and industrial uses (M\&I), hydroelectricity generation, irrigation, navigation, etc. (Fig. 1). Storage services, on the other hand, are associated with reservoirs and their ability to move water over time in order to increase its availability when it becomes more valuable (e.g., during the low flow season). Because a given storage facility may be valuable for various water using activities, and to keep the accounting framework as general as possible, production and storage services are individually considered. In other words, the framework rests on the assumption that each activity, whether it is production or storage, can be represented by a separate economic agent.

To illustrate those concepts and for notational simplicity, we will imagine a system with a cascade of $J$ multipurpose reservoirs as depicted in Fig. 2. The water stored in each reservoir can be used for both consumptive (e.g., irrigation) and non-consumptive uses (e.g., hydropower generation). Let us further imagine that this system is managed by a river basin authority (RBA) whose mandate would essentially consist in (i) efficiently allocating water between the different elements of the system and (ii) preserving the hydrologic integrity of the river basin and thus ensuring the quality of the hydrologic services (here the production of blue water). Finally, note that the elements of the system depicted in Fig. 2 are independent economic agents; there are $J$ reservoir operators, $J$ irrigation district associations, $J$ power companies and one river basin authority.

In that system, the economic value of a service, whether it is storage or production, corresponds to a hypothetical transaction between two hydraulically connected agents: the upstream seller and the downstream buyer. The transactions are hypothetical because they are not observed in practice; they 

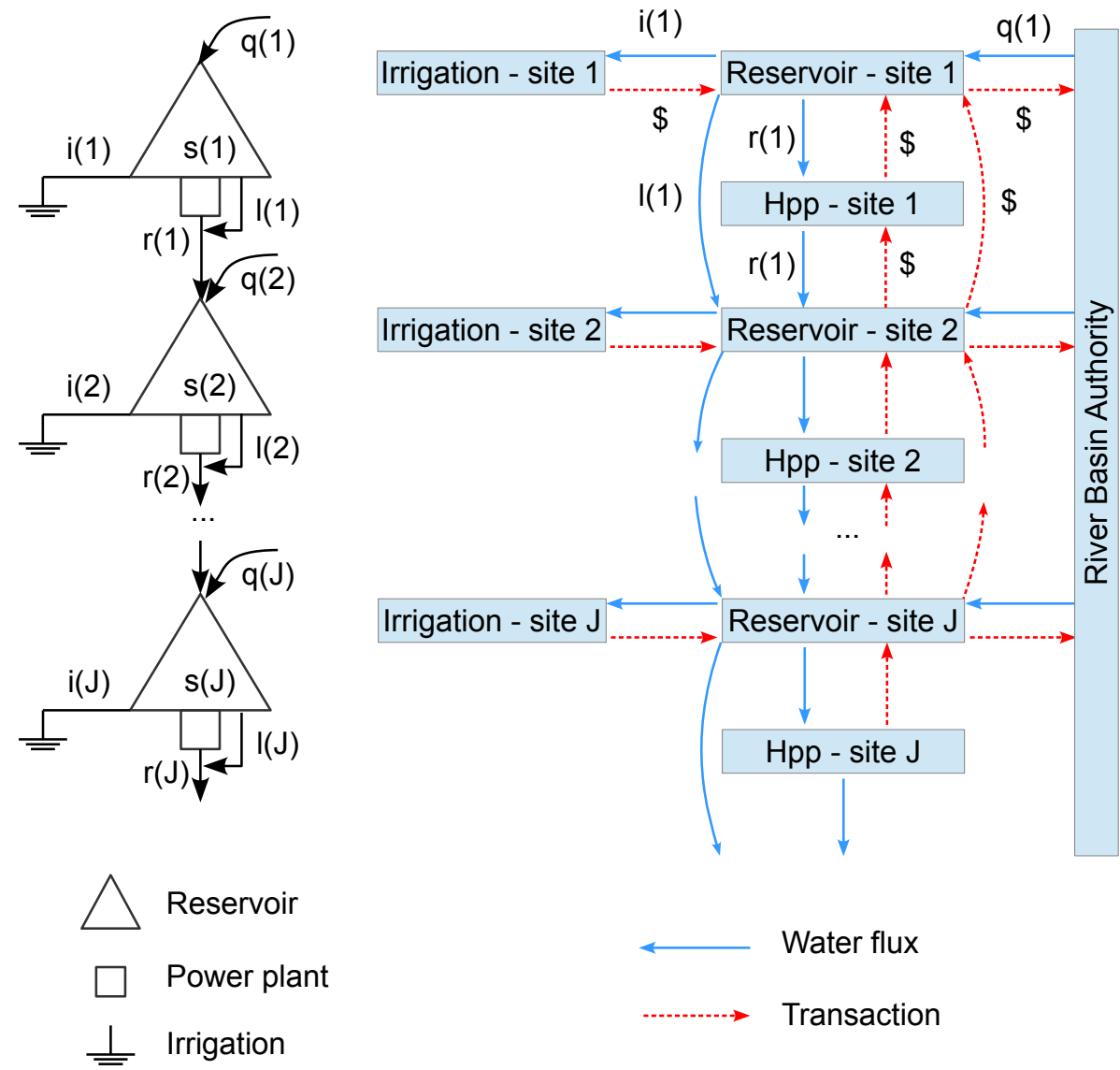

Figure 2. Cascade of $J$ multireservoirs - water fluxes and financial transactions.

are implicit to the economically efficient allocations identified by the hydro-economic model. In other words, a financial transaction always accompanies a water flux but in the opposite direction, as illustrated in Fig. 2. The clearing prices of those transactions are the MROC $\left(\lambda_{t}\right)$. Similarly, the economic value of blue water at site $j$, i.e., the natural runoff generated over the area drained by reservoir $j$, is given by the product between $\boldsymbol{q}_{t}(j)$ and $\lambda_{t}(j)$.

To summarize, the transactions are based on the following principles:

- RBA sells to the $J$ reservoirs the natural flows $\boldsymbol{q}_{t}(1), \boldsymbol{q}_{t}(2), \ldots, \boldsymbol{q}_{t}(J)$ at a price of $\lambda_{t}(1), \lambda_{t}(2), \ldots, \lambda_{t}(J)$, respectively. RBA charges for the water entering the system in order to cover the costs associated with its mandates (e.g., conservation, coordination, compensation, etc.).

- Reservoir $j$ sells to the hydropower plant $j$, denoted $\mathrm{HPP}_{j}$, a volume $\boldsymbol{r}(j)$ at a price of $\lambda_{t}(j)$. Here, a reservoir charges the hydropower station for the volume of water released through the turbines. The price is the marginal value of the water kept in storage.
- Reservoir $j$ sells to the irrigators $j\left(\operatorname{IDA}_{j}\right)$ a volume $i(j)$ at a price $\lambda_{t}(j)$.

- The downstream reservoir $j+1$ buys a volume $\boldsymbol{r}(j)$ at a price $\lambda_{t}(j+1)$ from the hydropower plant $j$. The water that was bought by the hydropower plant from the upstream reservoir can be sold back to the downstream reservoir but at a price corresponding to the value of water in that reservoir.

To illustrate how the transactions are calculated for the hypothetical system shown in Fig. 2, one must start with the upstream reservoir (site 1) whose water balance equation is

$$
\Delta s_{t}(1)-e_{t}(1)=r_{t}(1)+l_{t}(1)+i_{t}(1)-\boldsymbol{q}_{t}(1),
$$

where $\boldsymbol{i}_{t}, \boldsymbol{e}_{t}$ and $\boldsymbol{l}_{t}$ are irrigation water withdrawals, evaporation losses and spillage losses, respectively. The financial transactions between the institutions around this reservoir are based on

$$
\begin{aligned}
\lambda_{t}(1)\left(\Delta \boldsymbol{s}_{t}(1)-\boldsymbol{e}_{t}(1)\right) & =\underbrace{\lambda_{t}(1) \boldsymbol{r}_{t}(1)}_{\mathrm{HPP}_{1}}+\underbrace{\lambda_{t}(1) l_{t}(1)}_{\mathrm{RBA}} \\
& +\underbrace{\lambda_{t}(1) \boldsymbol{i}_{t}(1)}_{\mathrm{IDA}_{1}}-\underbrace{\lambda_{t}(1) q_{t}(1)}_{\mathrm{RBA}},
\end{aligned}
$$


where the signs + and - mean that the reservoir is "selling to" and "buying from", respectively. In the previous equation we can see that the reservoir is selling $\boldsymbol{r}_{t}(1)$ to the hydropower company that owns the hydropower plant 1 $\left(\mathrm{HPP}_{1}\right), \boldsymbol{l}_{t}(1)$ to reservoir 2 through RBA, $\boldsymbol{i}_{t}(1)$ to the irrigation district 1 , and is buying $\boldsymbol{q}_{t}(1)$ from RBA.

Then, for the immediately downstream reservoir 2 we have $\Delta \boldsymbol{s}_{t}(2)-\boldsymbol{e}_{t}(2)=\boldsymbol{r}_{t}(2)+\boldsymbol{l}_{t}(2)+\boldsymbol{i}_{t}(2)-\boldsymbol{q}_{t}(2)-\boldsymbol{r}_{t}(1)-\boldsymbol{l}_{t}(1)$, and

$$
\begin{aligned}
\lambda_{t}(2)\left(\Delta \boldsymbol{s}_{t}(2)-\boldsymbol{e}_{t}(2)\right) & =\underbrace{\lambda_{t}(2) \boldsymbol{r}_{t}(2)}_{\mathrm{HPP}_{2}}+\underbrace{\lambda_{t}(2) \boldsymbol{l}_{t}(2)}_{\mathrm{RBA}} \\
& +\underbrace{\lambda_{t}(2) \boldsymbol{i}_{t}(2)}_{\mathrm{IDA}_{2}}-\underbrace{\lambda_{t}(2) \boldsymbol{q}_{t}(2)}_{\mathrm{RBA}} \\
& -\underbrace{\lambda_{t}(2) \boldsymbol{r}_{t}(1)}_{\mathrm{HPP}_{1}}-\underbrace{\lambda_{t}(2) \boldsymbol{l}_{t}(1)}_{\mathrm{RBA}} .
\end{aligned}
$$

The main difference with the most upstream reservoir 1 is that the downstream reservoir (here reservoir 2) is now buying water coming from the immediately upstream reservoir (here reservoir 1). We can compute these balances until we reach the last reservoir $J$ where

$\Delta \boldsymbol{s}_{t}(J)=\boldsymbol{r}_{t}(J)+\boldsymbol{l}_{t}(J)+\boldsymbol{i}_{t}(J)-\boldsymbol{q}_{t}(J)-\boldsymbol{r}_{t}(J-1)+\boldsymbol{l}_{t}(J-1)$,

and

$$
\begin{aligned}
\lambda_{t}(J) \Delta \boldsymbol{s}_{t}(J) & =\underbrace{\lambda_{t}(J) \boldsymbol{r}_{t}(J)}_{\mathrm{HPP}}+\underbrace{\lambda_{t}(J) \boldsymbol{l}_{t}(J)}_{\mathrm{RBA}} \\
& +\underbrace{\lambda_{t}(J) \boldsymbol{i}_{t}(J)}_{\mathrm{IDA}_{J}}-\underbrace{\lambda_{t}(J) \boldsymbol{q}_{t}(J)}_{\mathrm{RBA}} \\
& -\underbrace{\lambda_{t}(J) \boldsymbol{r}_{t}(J-1)}_{\mathrm{HPP}_{J-1}}-\underbrace{\lambda_{t}(J) \boldsymbol{l}_{t}(J-1)}_{\mathrm{RBA}} .
\end{aligned}
$$

Once those transactions are calculated, the water accounts can be established for various spatial and temporal scales depending on the policy objective at hand. The multireservoir system in the Eastern Nile River basin will be used to illustrate the framework.

\subsection{The Eastern Nile River basin}

As its name indicates, the Eastern Nile River basin drains the Eastern part of the Nile Basin, a region that covers much of Ethiopia, Sudan and Egypt. The Eastern Nile River basin includes the Blue Nile, the Baro-Akobo-Sobat, the Atbara and the main Nile, i.e., the entire Nile Basin except the White Nile, which drains the equatorial lakes (Fig. 3). The hydrological regime of the Blue Nile and the Atbara is characterized by a very high seasonal and interannual variability, while the White Nile has more constant discharges. With more than $70 \%$ of the annual discharge of the Nile coming from these two highly variable rivers, the Blue Nile and the Atbara (Sutcliff and Parks, 1999), Egypt would be exposed to significant

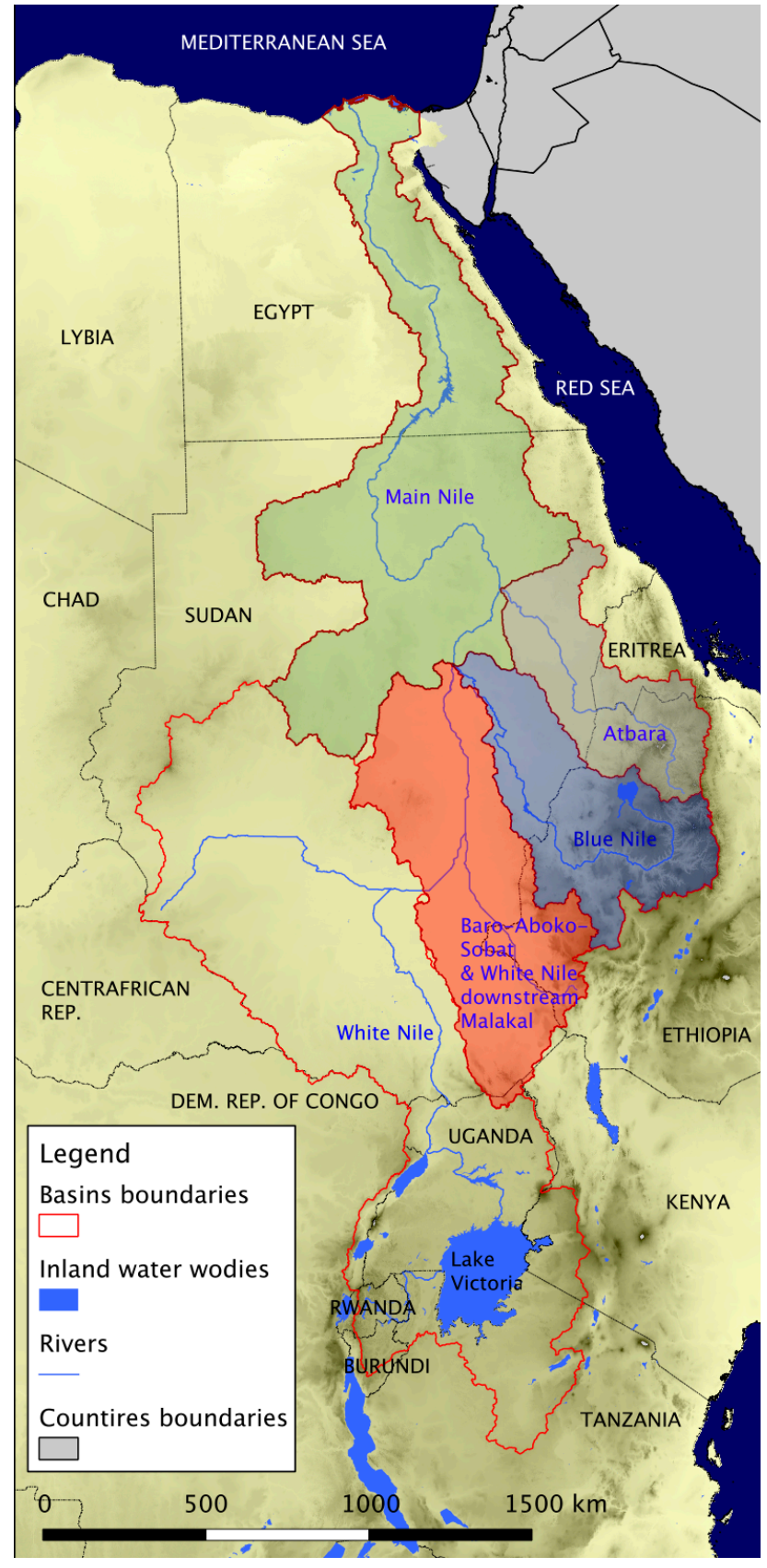

Figure 3. The Eastern Nile River basin.

hydrological risk without the High Aswan Dam (HAD) and its multiyear storage capacity.

The dominant uses of the Nile waters are irrigated agriculture and hydropower generation, which are mostly taking place in Egypt and Sudan. The largest hydraulic infrastructures are listed in Table 1 and the current largest reservoir is Lake Nasser in Egypt (HAD). If the two downstream riparian countries currently have the lion's share in terms of irrigated agriculture and hydropower generation, this is likely to change in the near future as Ethiopia is now developing 
Table 1. Main completed dams and hydropower plants in the Eastern Nile River basin.

\begin{tabular}{llcrc}
\hline Name (Country) & River & Live storage $\left(\mathrm{hm}^{3}\right)$ & Capacity (MW) & Lateral irrigation (yes/no) \\
\hline Tis Abbay I and II (ET) & Blue Nile & 0 (run of river) & 86 & no \\
Tana Beles link (ET) & Blue Nile & 0 (run of river) & 270 & no \\
TK-5 (ET) & Atbara & 9200 & 300 & no \\
Roseires (SU) & Blue Nile & 6900 & 275 & no \\
Sennar (SU) & Blue Nile & 480 & 15 & yes \\
Khashm el Girba (SU) & Atbara & 630 & 17 & yes \\
Jebel Aulia (SU) & White Nile & 2800 & 30 & yes \\
Merowe (SU) & Main Nile & 8300 & 1250 & no \\
High Aswan Dam - HAD (EG) & Main Nile & 105900 & 2100 & no \\
Old Aswan Dam (EG) & Main Nile & 0 (run of river) & 500 & no \\
Esna (EG) & Main Nile & 0 (run of river) & 90 & no \\
\hline
\end{tabular}

major infrastructural projects in the Blue Nile Basin such as the Tana Beles irrigation/hydropower project and the Grand Ethiopian Renaissance Dam (GERD). The latter will have a storage capacity of $65 \mathrm{~km}^{3}$ (more than the annual flow at the border between Ethiopia and Sudan) and a power station of $5000 \mathrm{MW}$. Other power stations further upstream on the Blue Nile are also on the drawing board in Ethiopia. The topology of the system with these recent ongoing and planned developments is depicted in Fig. 4.

The hydro-economic model of the Eastern Nile Basin is based on the schematization shown in Fig. 4. The schematization of Baro-Akobo-Sobat is not included in Fig. 4 as this sub-basin is still natural, with no/minimal water resources development. The allocation decisions are chosen to maximize expected net economic returns from irrigated agriculture and hydropower generation over a planning horizon of 10 years and for 30 different hydrologic scenarios. In SDDP (Stochastic Dual Dynamic Programming), a built-in hydrologic model can be used to generate, among other things, synthetic flow sequences (scenarios) that are needed to simulate the system for various hydrologic conditions. Using synthetic flow series, instead of historical ones, allows us to increase the number of simulations in order to get smoother empirical statistical distributions of the results (allocation decisions and MROC). The disadvantages are mainly related to the structure of the hydrologic model, a periodic autoregressive model with cross-correlated residuals, which does not necessarily preserve the long-term memory of the hydrologic processes Since the objective of this study is not to mimic current allocation policies, we made the assumption that countries would cooperate in order to maximize basinwide benefits. Under this assumption, the stochastic multistage decision-making problem (Eqs. 1-4) can be solved, for example, by stochastic dual dynamic programming. This algorithm has been described in details in Goor et al. (2010) and in Marques and Tilmant (2013). Note that the proposed accounting framework could be established with the help of any other hydro-economic model, centralized or decentralized, as long as it provides allocation decisions and the cor- responding MROC. For this case study, at each time step $t$, the allocation decisions are the vector $s_{t+1}$ of storage at the end of time $t$, the vector of reservoir releases $\boldsymbol{r}_{t}$, the vector of spillage losses $\boldsymbol{l}_{t}$ and the vector of irrigation withdrawals $i_{t}$.

\section{Analysis of simulation results}

The analysis of SDDP-derived simulation results will be done for year 5 only, in order to avoid the effects of the boundary conditions, i.e., the initial storage volumes and the zero terminal value function (Goor et al., 2010). After convergence of the SDDP algorithm, a variety of results including MROC, outflows, storage levels and evaporation losses are available at each node of the system.

To illustrate the water accounting framework, we will first examine the following items on an annual basis:

- The value of blue water at site $j: \lambda_{t}(j) \cdot \boldsymbol{q}_{t}(j)$. This is the economic value of runoff generated between node $j$ and the immediately upstream node(s). This information could be used, for example, to prioritize soil and water conservation measures in the river basin.

- The opportunity cost of evaporation losses at site $j$ : $\lambda_{t}(j) \cdot \boldsymbol{e}_{t}(j)$. It corresponds to the benefits forgone faced by downstream agents due to evaporation losses from a man-made reservoir at site $j$.

- The opportunity cost of irrigation withdrawals at site $j$ $\left(\boldsymbol{\lambda}_{t}(j) \cdot \boldsymbol{i}_{t}(j)\right)$ is the benefits forgone in the basin due to the consumptive use at site $j$.

- The value of turbined outflows at site $j\left(\lambda_{t}(j) \cdot \boldsymbol{r}_{t}(j)\right)$ gives the economic value of non-consumptive use at site $j$.

Table 2 lists the average annual water accounts for the Eastern Nile Basin for the items listed above, while Fig. 5 provides a spatial distribution of the average annual water accounts. 
Table 2. Annual water accounts in USD million - Eastern Nile Basin.

\begin{tabular}{|c|c|c|c|c|c|}
\hline Country & Node & Blue water & Hydropower & Irrigation & Evaporation \\
\hline \multirow[t]{9}{*}{ Ethiopia } & Lake Tana & 450 & 0 & 0 & 0 \\
\hline & Tis Abbay I\&II & 0 & 1 & 0 & 0 \\
\hline & Tana Beles & 0 & 69 & 0 & 0 \\
\hline & Tana Beles irrigation & 0 & 0 & 12 & 0 \\
\hline & Karadobi & 1555 & 0 & 0 & 0 \\
\hline & Beko-Abo & 176 & 0 & 0 & 0 \\
\hline & Mendaya & 1285 & 0 & 0 & 0 \\
\hline & GERD & 1854 & 897 & 0 & 78 \\
\hline & TK-5 & 303 & 47 & 0 & 0 \\
\hline Sub-total & & 5623 & 1013 & 12 & 78 \\
\hline \multirow[t]{8}{*}{ Sudan } & Roseires & 0 & 0 & 0 & 62 \\
\hline & Upstream Sennar & 0 & 0 & 236 & 0 \\
\hline & Sennar & 0 & 0 & 531 & 28 \\
\hline & Downstream Sennar & 527 & 0 & 88 & 0 \\
\hline & Khashm El Girba & 899 & 1 & 189 & 0 \\
\hline & Jebel Aulia & 2530 & 0 & 117 & 253 \\
\hline & Nile - evaporation 1 & 0 & 0 & 74 & 0 \\
\hline & Merowe & 0 & 282 & 0 & 119 \\
\hline Subtotal & & 3957 & 283 & 1236 & 462 \\
\hline \multirow[t]{4}{*}{ Egypt } & HAD & 0 & 524 & 62 & 1011 \\
\hline & Old Aswan Dam (I\&II) & 0 & 160 & 0 & 0 \\
\hline & Esna & 0 & 10 & 0 & 0 \\
\hline & Delta & 0 & 0 & 4832 & 0 \\
\hline Subtotal & & 0 & 693 & 4895 & 1011 \\
\hline Total & & 9580 & 1989 & 6143 & 1551 \\
\hline
\end{tabular}

The analysis of these items reveals that the average annual economic value of blue water in Ethiopia is worth more than USD 5.6 billion, which is significantly more than the amount measured in Sudan (USD 3.9 billion). This is due to the combined effect of two factors: (1) as indicated above, much of the Nile waters are generated in Ethiopia, and (2) the marginal value of water in Ethiopia is the highest due to the presence of a cascade of hydropower plants from the border with Sudan down to the Mediterranean Sea. Note that a significant portion of the value of blue water in Sudan corresponds to the White Nile originating from the equatorial lakes but entering the system at Khartoum to form the Nile River. In other words, if the water accounts were to be established for the entire Nile Basin, much of that amount (USD 2.53 billion) would actually be located in the headwaters of the White Nile (Uganda, Rwanda, Burundi, Tanzania, Kenya).

Despite much lower storage capacity, the annual opportunity costs of evaporation losses from man-made reservoirs in Sudan are significantly higher than those in Ethiopia: USD 462 million versus 78 million, respectively. This is due to the fact that the evaporative power of the atmosphere is much lower in Ethiopia than in Sudan. Again, this result in- dicates that large reservoirs should be built upstream. Note that Lake Tana is considered here as a natural reservoir. For Lake Nasser in Egypt, the opportunity cost is also significant (about USD 1 billion per year, twice as much as Sudan) due to the combined effect of inadequate topography and dry climatic conditions.

For the irrigation activities, the average annual economic value of bulk water in Egypt is about USD 5 billion, which is consistent with MWRI (2005). In Sudan, the opportunity cost of water diverted to the irrigation schemes exceeds USD 1.2 billion per year, which is still a hundred times higher than that in Ethiopia (USD 12 million). With the economic parameters chosen for this study, it does not appear to be economically efficient to irrigate in Ethiopia where the MROC of water is high due to the presence of a cascade of non-rival uses downstream. This result shows that, from an economic standpoint, irrigation should take place downstream, after water has been used for hydropower generation in Ethiopia (Whittington et al., 2005).

The economic value of bulk water used for the production of hydroelectricity reaches, on average, almost USD 1 billion in Ethiopia, 283 million in Sudan and 693 million in Egypt. These amounts are directly proportional to the productivity 


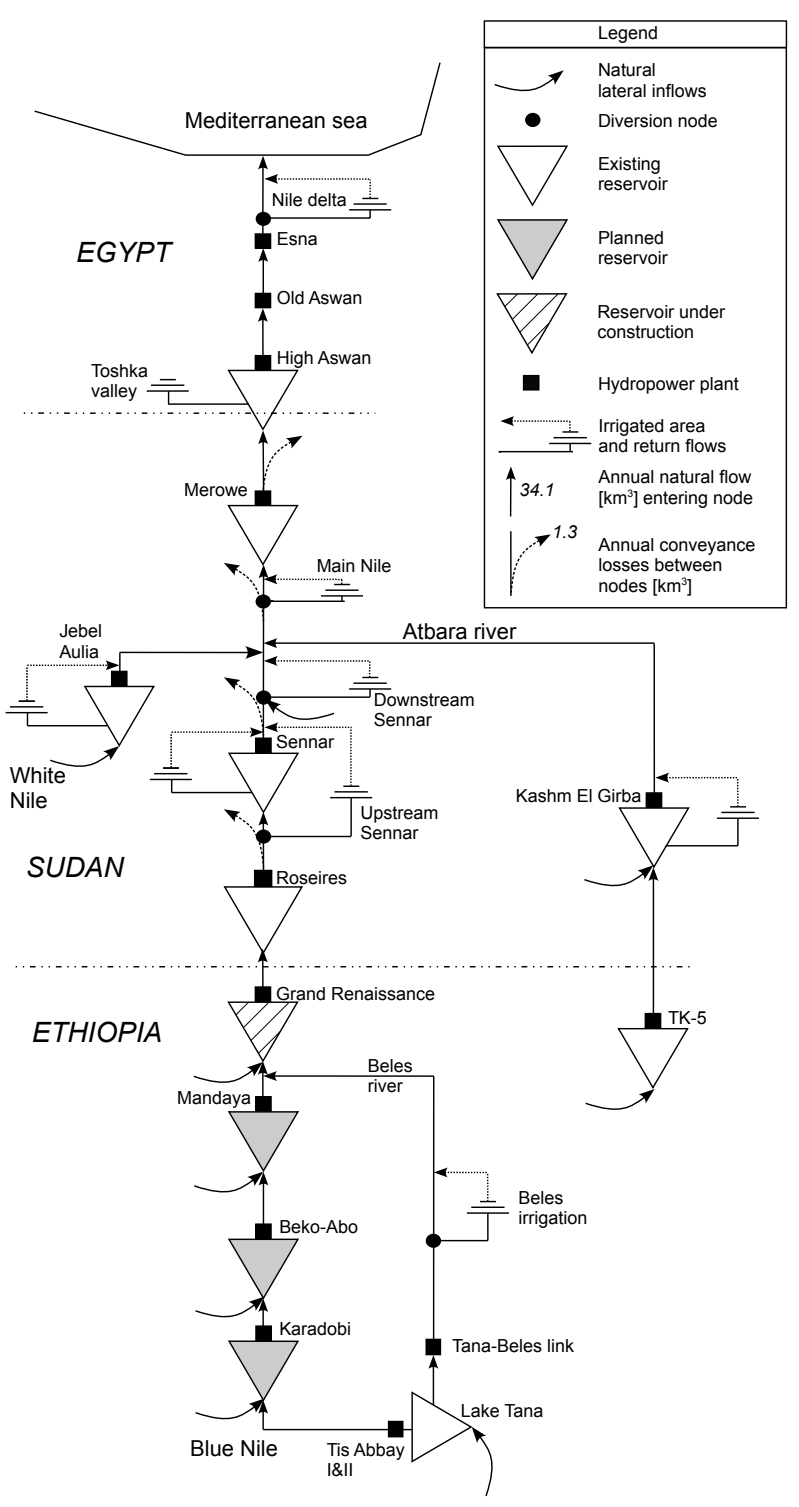

Figure 4. Schematization of the Eastern Nile River basin.

(MW m ${ }^{-3} \mathrm{~s}^{-1}$ ) of the power stations which, in turn, is influenced by the topography (the unit productivity increases with the head on turbines and thus with the hydraulic gradient).

On a shorter time step, it might be interesting to assess the value of storage services at site $j$. This is the economic value associated with water transfers over time, i.e., from the highflow to the low-flow season, at a particular site in the basin. Here, again, the benefits and costs are felt by downstream agents. In terms of storage, when GERD is online, Ethiopia will be able to smooth the imbalances between supplies and demands throughout much of the basin. Those storage services are worth on average USD 891 million per year. This is significantly higher than the combined value of storage services in Sudan and Egypt, which are valued at USD 79 million and 228 million per year, respectively. This stresses the

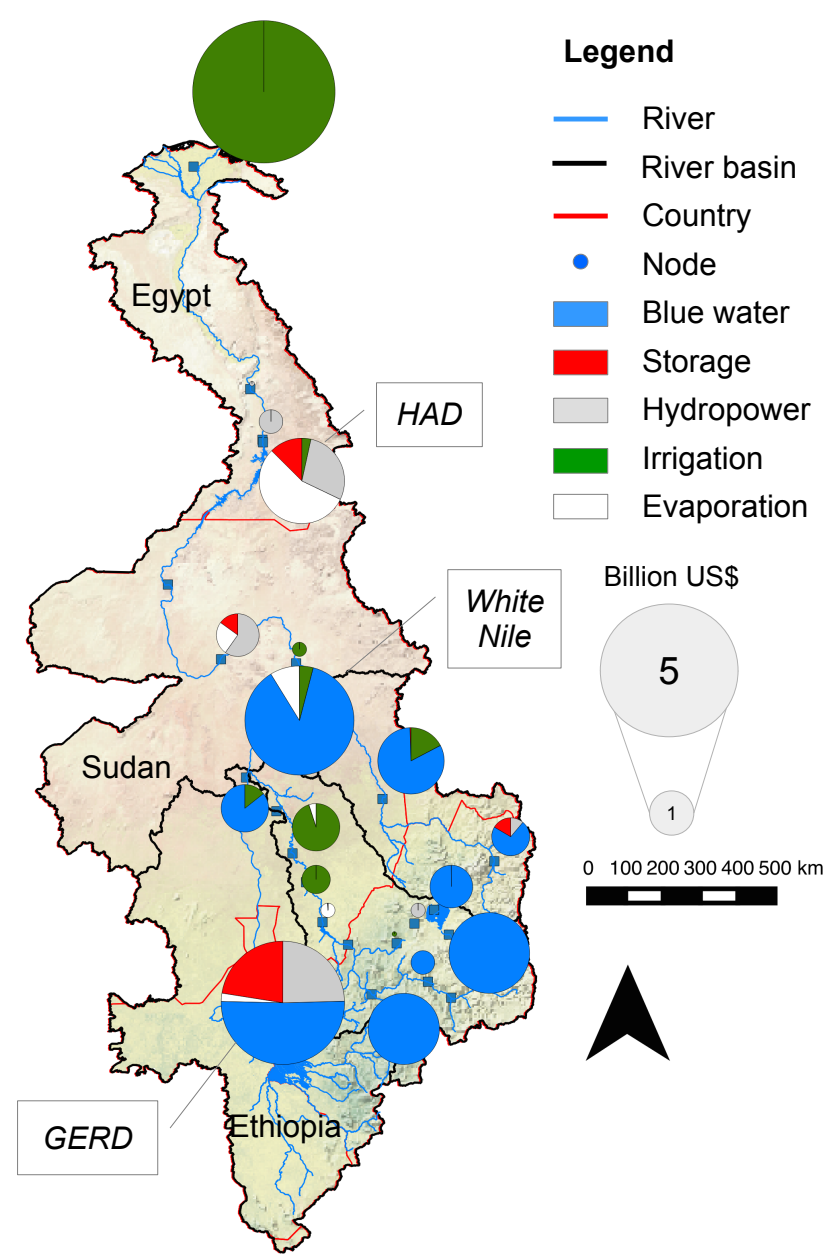

Figure 5. Average annual water accounts - Eastern Nile River basin.

importance of storing water as far upstream as possible in order take advantage of the hydraulic gradient and to have the largest number of water users downstream who can benefit from regulated flows (Whittington et al., 2005).

Figure 6 shows the average monthly values of blue water at key nodes throughout the basin. The first layers in dark blue are the incremental flows at the different nodes on the Blue Nile in Ethiopia (Fig. 4). The contribution of the Dinder and Rahad rivers, the last tributaries of the Blue Nile before the confluence with the White Nile in Sudan are in light blue. The two nodes of the Atbara branch, which flows from Ethiopia though Sudan, are in red. Finally, the White Nile is in grey. In August, during the high flow season, the economic value of runoff almost reaches USD 2.5 billion with more than $70 \%$ coming from Ethiopia (dark blue). During the low flow season, the economic value of the Blue Nile is negligible compared to the White Nile. In April, for instance, the Blue Nile only contributes to $22 \%$ of the economic value of runoff in the basin. Those monthly economic values follow closely the hydrological regime discussed in the previ- 


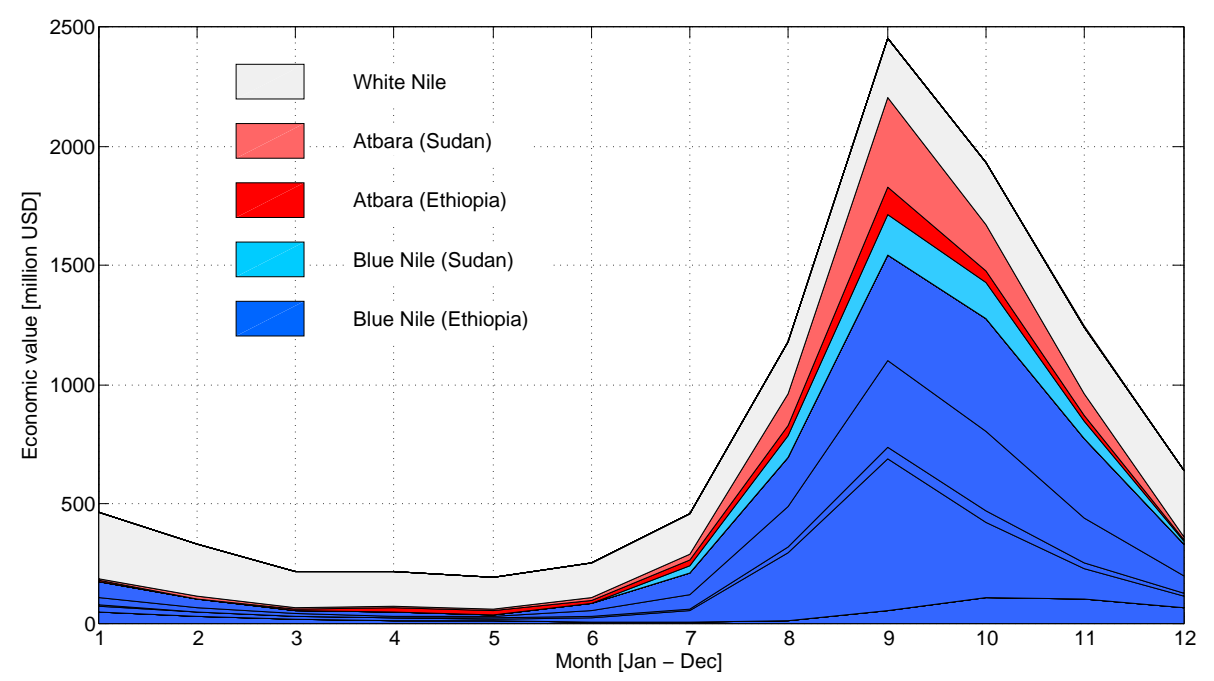

Figure 6. Average monthly values of blue water in the basin.

ous section because two large reservoirs in the system, HAD and GERD, tend to equalize the marginal water values across time periods (equimarginal principle).

\section{Conclusions}

This paper proposes an alternative approach to establish water accounts in multipurpose multireservoir systems. The approach exploits the results of traditional, optimization-based, hydro-economic models such as allocation decisions and marginal water values (marginal resource opportunity cost). By keeping track of the product between the water fluxes and their corresponding water values, it is possible to establish water accounts reflecting the scarcity of water. The approach is illustrated with the Eastern Nile River basin in Africa where the dominant uses are hydropower generation and irrigation.

The results indicate that the average annual economic value of runoff corresponds to USD 9.5 billion, which can then be split between irrigation activities (USD 6.1 billion), hydropower (almost USD 2 billion) and evaporation losses from man-made reservoirs (USD 1.5 billion). The approach makes it also possible to analyze the contribution of storage services to the overall value of the system. For the case study, the Grand Ethiopian Renaissance Dam, which is currently under construction on the Blue Nile, could provide as much as USD 821 million of storage services annually.

The proposed approach could be implemented with any hydro-economic model as long as water fluxes and marginal water values are computed. In this study we made an important assumption; namely, that basin-wide allocation is economically efficient. This assumption could be relaxed if a decentralized hydro-economic model were to be available for this case study. It would allow us to establish water accounts for various levels of cooperation and institutional complexity in the basin.

More complex hydrologic processes, such as infiltration, rainfall and subsurface flows, could also be valued if they are adequately represented in the hydro-economic model. However, despite recent advances in the field of optimization, there will always be a trade-off between model complexity and applicability. For the case study, it was beyond the scope of the present research effort to include more complex hydrological processes at the scale of that river basin.

Acknowledgements. The authors thank the reviewers, and the Editor for their constructive comments.

Edited by: G. Characklis

\section{References}

Brouwer, R. and Hofkes, M.: Integrated hydro-economic modelling: Approaches, key issues and future research directions, Ecol. Econ., 66, 16-22, 2008.

Brown, T., Harding, B. and Payton, E.: Marginal economic value of streamflow: A case study for the colorado river basin, Water Resour. Res., 26, 2845-2859, 1990.

Goor, Q., Halleux, C., Mohamed, Y., and Tilmant, A.: Optimal operation of a multipurpose multireservoir system in the Eastern Nile River Basin, Hydrol. Earth Syst. Sci., 14, 1895-1908, doi:10.5194/hess-14-1895-2010, 2010.

Griffin, R.: Water Resource Economics: The Analysis of Scarcity, Policies, and Projects, The MIT Press, Cambridge, USA, 2006.

Harou, J., Pulido-Velazquez, M., Rosenberg, D., Medelling-Azuara, J., Lund, J., and Howitt, R.: Hydro-economic models: concepts, design, applications, and future prospects, J. Hydrol., 375, 627643, 2009. 
Heinz, I., Pulido-Velazquez, M., Lund, J., and Andreu, J.: Hydroeconomic modeling in river basin management: Implications and applications for the european water framework directive, Water Resour. Manag., 21, 1103-1125, 2007.

Jenkins, M., Lund, J., Howitt, R., Draper, A., Msangi, S., Tanaka, S., Ritzema, R., and Marques, G.: Optimization of california's water supply system: results and insights, J. Water Res. Pl.-ASCE, 130, 271-280, 2004.

Karimi, P., Bastiaanssen, W. G. M., and Molden, D.: Water Accounting Plus (WA+) - a water accounting procedure for complex river basins based on satellite measurements, Hydrol. Earth Syst. Sci., 17, 2459-2472, doi:10.5194/hess-17-24592013, 2013a.

Karimi, P., Bastiaanssen, W. G. M., Molden, D., and Cheema, M. J. M.: Basin-wide water accounting based on remote sensing data: an application for the Indus Basin, Hydrol. Earth Syst. Sci., 17, 2473-2486, doi:10.5194/hess-17-2473-2013, 2013b.

Kiptala, J., Mohamed, Y., Mul, M., and van der Zaag, P.: Multiobjective analysis of the green-blue water uses in a highly utilized basin in africa, Tech. rep., UNESCO-IHE, Delft, the Netherlands, 2014.

Kirby, M. and Mainuddin, M.: Water productivity assessment: Mekong river basin approach, Tech. rep., CGIAR Challenge Program on Water and Food., Colombo, Sri Lanka, 2006.

Lange, G.-M., Mungatana, E., and Hassan, R.: Water accounting for the orange river basin: An economic perspective an managing a transboundary resource, Ecol. Econ., 61, 660-670, 2007.

Marques, G. and Tilmant, A.: The economic value of coordination in large-scale multireservoir systems: the parana river case, Water Resour. Res., 49, 1-12, 2013.

Molden, D.: Accounting for water use and productivity, Tech. Rep. 1, International Irrigation Management Institute, Colombo, Sri Lanka, 1997.

Molden, D. and Sakthivadivel, R.: Water accounting to assess use and productivity of water, Int. J. Water Resour. D., 15, 55-71, 1999.
MWRI: National water resources plan 2017, Tech. rep., Ministry of Water Resources and Irrigation, Arab Republic of Egypt, 2005.

Pande, S., van den Boom, B., Savenije, H., and Gosain, A.: Water valuation at basin scale with application to western india, Ecol. Econ., 70, 2416-1438, 2011.

Pulido-Velazquez, M., Alvarez-Mendiola, E., and Andreu, J.: Design of efficient water pricing policies integrating basinwide resource opportunity costs, J. Water Res. Pl.-ASCE, 139, 583-592, 2013.

Seyam, I.,Hoekstra, A., and Savenije, H.: Calculation methods to assess the value of upstream water flows and storage as a function of downstream benefits, Phys. Chem. Earth, 27, 977-982, 2002.

Sutcliff, J. and Parks, Y.: The Hydrology of the Nile, IAHS Publications, Wallingford, UK, 1999.

Tilmant, A., Pinte, D., and Goor, Q.: Assessing marginal water values in multipurpose multireservoir systems via stochastic programming, Water Resour. Res., 44, W12431, doi:10.1029/2008WR007024, 2008.

Tilmant, A., Arjoon, D., and Marques, G.: The economic value of storage in multireservoir systems, J. Water Resour Plann. Manage., 140, 375-383, doi:10.1061/(ASCE)WR.19435452.0000335, 2012.

Vardon, M., Lenzen, M., Peevor, S., and Creaser, M.: Water accounting in australia, Ecol. Econ., 61, 650-659, 2007.

Whittington, D., Wu, X., and Sadoff, C.: Water resources management of the nile basin: the economic value of cooperation, Water Policy, 7, 227-252, 2005.

Young, R.: Determining the Economic Value of Water - Concepts and Methods, Resources for the Future, Resources for the Future (RFF Press), Washington, USA, 2005.

Zhu, Z., Giordano, M., Cai, X., and Molden, D.: The yellow river basin: water accounting, water accounts, and current issues, Water Int., 29, 2-10, doi:10.1080/02508060408691742, 2009. 